\title{
A 43-GHz AlInAs/GaInAs/InP HEMT Grid Oscillator
}

\author{
Polly Preventza, ${ }^{1}$ Mehran Matloubian, ${ }^{2}$ and David B. Rutledge, ${ }^{1}$ \\ ${ }^{1}$ Department of Electrical Engineering, California Institute of Technology, Pasadena CA 91125 \\ ${ }^{2}$ Hughes Research Laboratories, Malibu CA 90265
}

\begin{abstract}
A 36-element hybrid grid oscillator has been fabricated. The active devices are InP-based High Electron Mobility Transistors (HEMT's). The grid oscillates at $43 \mathrm{GHz}$ with an effective radiated power of $200 \mathrm{~mW}$. Measurements show the $E$ and $H$-plane radiation patterns have side lobes $10 \mathrm{~dB}$ below the main beam. These results are a significant improvement over a previous millimeter-wave grid oscillator, which had a divided beam because of substrate modes.
\end{abstract}

\section{INTRODUCTION}

In order to produce high power at microwave and millimeter-wave frequencies the output powers of many solid-state devices are combined. Quasi-optical freespace power combiners eliminate losses associated with waveguides and transmission lines. Quasi-optical grid oscillators are periodic, strongly coupled, oscillating structures based on integrating active devices directly into a planar array. Fig. 1 shows the approach. The first grid oscillator was a 5-GHz 100-MESFET grid demonstrated by Popovic et al. [1]. A 100-MESFET oscillator grid produced $10 \mathrm{~W}$ at $10 \mathrm{GHz}$ [2]. A monolithic grid was demonstrated that oscillated at $35 \mathrm{GHz}$ [3]. The E-plane radiation pattern of this grid is shown in

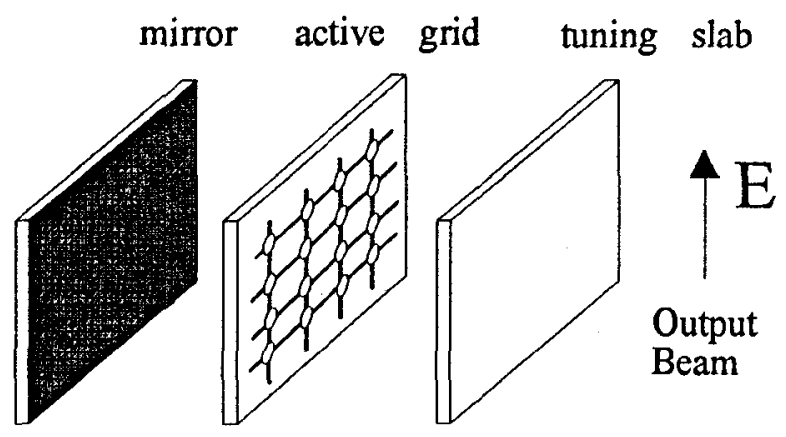

Fig. 1. A grid oscillator. The mirror and the dielectric slab provide tuning and help the devices to lock together.

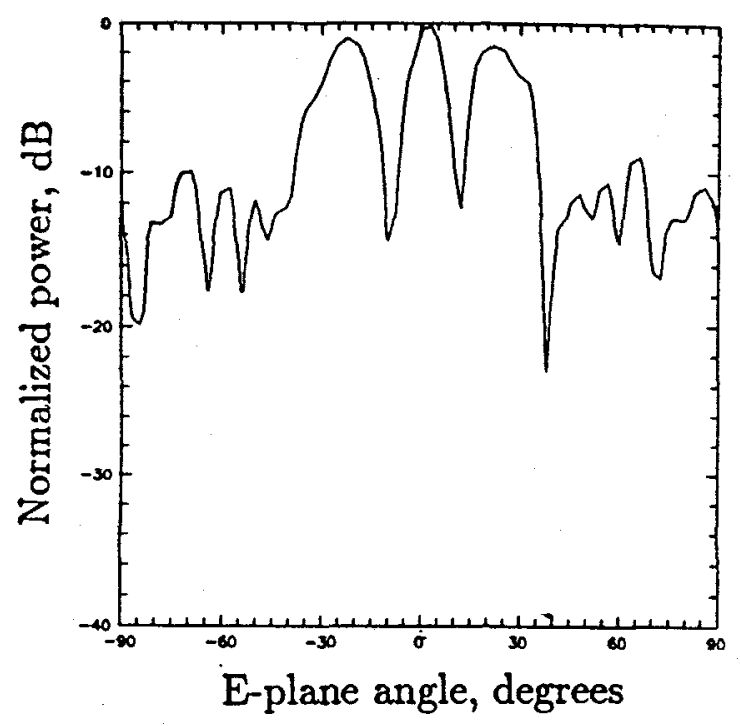

Fig. 2. E-plane radiation pattern of a 36-element monolithic grid oscillator operating at $35 \mathrm{GHz}[3,4]$.

Fig. 2. The side-lobes have a peak value only $2 \mathrm{~dB}$ less than the main-lobe peak. D.W. Griffin [5] pointed out that the unsatisfactory E-plane pattern is due to substrate-mode excitation that contributes to the radiation pattern through the edges of the grid.

In this paper the design and performance of a 36element InP HEMT grid oscillator is described. A photograph of the grid is shown in Fig. 3. The period of the grid and the electrical thickness of the substrate, control the substrate-mode excitation. To minimize the power in the substrate modes we use a thin $(254 \mu \mathrm{m})$ Duroid substrate with a dielectric constant of 2.2. This gives an electrical thickness at the oscillation frequency of only $19^{\circ}$. We also chose the vertical and horizontal period of the grid to minimize substrate-mode excitation. 


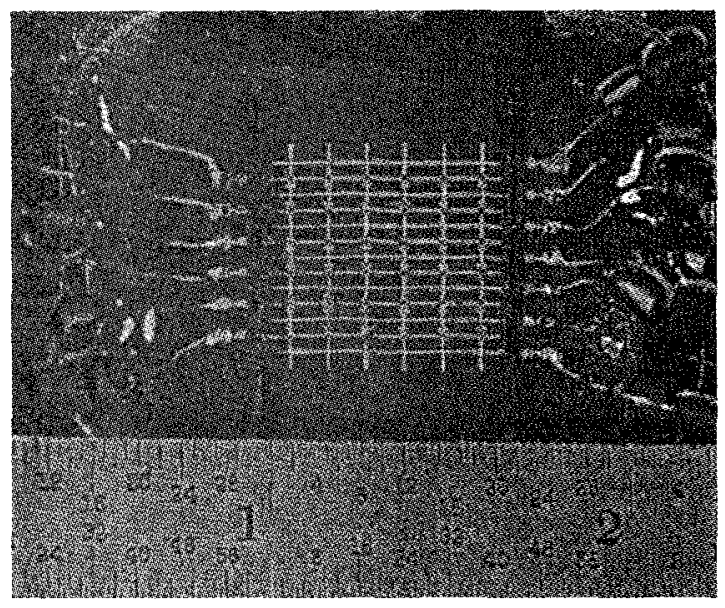

Fig. 3. Photograph of the 36-element hybrid HEMT grid oscillator. The horizontal lines are bias lines. Ferrite slabs are placed on each side of the grid underneath the bond wires to suppress oscillations at low frequencies. Ferrite beads are also added along the leads to suppress bias line oscillations.

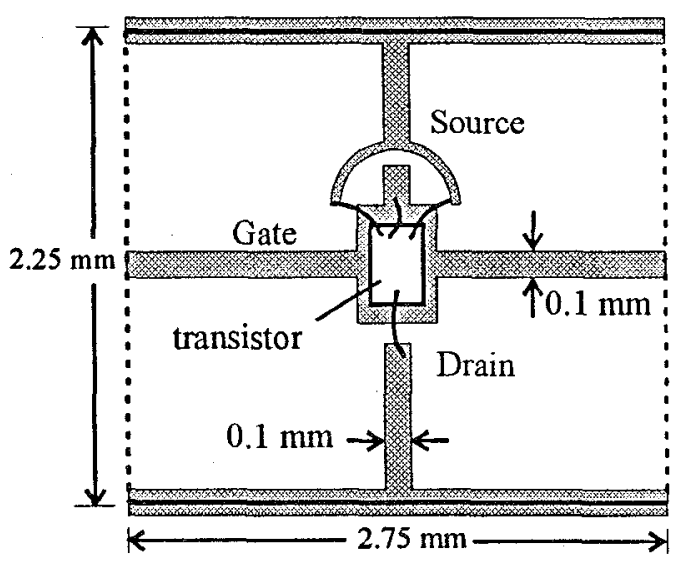

Fig. 4. The equivalent waveguide unit cell. Electric walls (solid lines) and magnetic walls (dashed lines) are imposed by symmetry on the boundaries of the unit cell. The drain and source of the devices are wire-bonded to the vertical leads. The gate is wire-bonded to the horizontal leads.

\section{DESIGN}

The devices are AlInAs/GaInAs on InP HEMT's fabricated at Hughes Research Laboratories. The HEMT's have a total gate width of $75 \mu \mathrm{m}[6,7]$. The devices have a peak transconductance of $848 \mathrm{mS} / \mathrm{mm}$ and a full channel current of $750 \mathrm{~mA} / \mathrm{mm}$ measured at a gate bias of $0.2 \mathrm{~V}$ and a drain bias of $1.5 \mathrm{~V}$.
In order to analyze the grid we assume that all devices are identical. Each device lies in an equivalent waveguide unit cell which is defined by the symmetry of the grid. This equivalent unit cell has magnetic walls on the sides and electric walls on the top and the bottom as shown in Fig. 4. The vertical spacing determines the excitation of TM modes and the horizontal spacing determines the TE mode power. We calculated the substrate-mode power for a $6 \times 6$ array of uniformly excited dipoles and another array with alternating $180^{\circ}$ phase shifts. We selected spacings that gave low substrate-mode power levels. The transmission-line equivalent circuit is shown in Fig. 5. The inductances and capacitances shown are calculated using the EMF method [8]. Free space is represented by $377-\Omega$ scaled by the aspect ratio $b / a$ of the unit cell. The circulator is inserted at the drain terminal to calculate the saturated circular function. This approach is described in [9]. The locus of the function crosses the zero-phase, unity-magnitude point at $44.3 \mathrm{GHz}$, indicating an oscillation at this frequency.

\section{PERFORMANCE}

An HP8563A spectrum analyzer with an HP11974series preselected mixer was used to measure the oscillation spectrum of the grid (Fig.7). An output tuner was placed in front of the grid that stabilized the signal and maximized the output power. The tuner used is a $\lambda_{0} / 4$-thick dielectric slab with a dielectric constant of 10.5 placed $6.5 \mathrm{~mm}$ in front of the grid. All devices in a single row are biased in parallel. Four separate dc supplies are used (one for each of the top and bottom rows, one for rows 2 and 3 , and another for rows 4 and 5). The separate supplies allowed us to control the angle of the

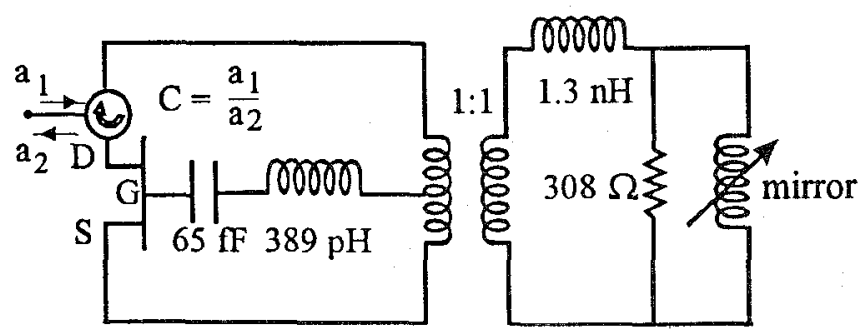

Fig. 5. Transmission-line equivalent circuit. The reflection coefficient at the circulator terminal calculates the circular function. The reactance of the mirror is determined by the thickness of the substrate and the spacing from the grid. 


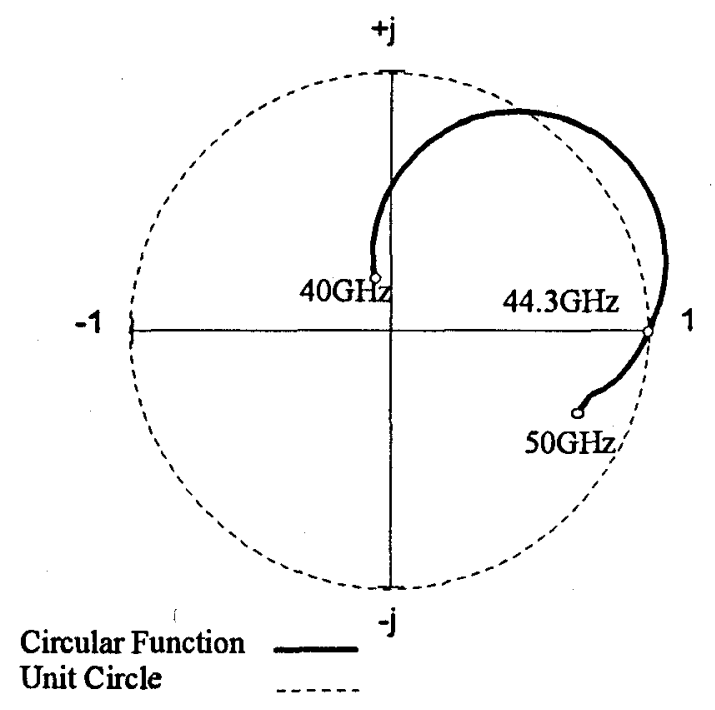

Fig. 6. Saturated circular function, $C$, of the grid. the oscilation criterion is satisfied at $44.3 \mathrm{GHz}$, where $C=1$.

beam. The oscillation frequency is $43 \mathrm{GHz}$, about $3 \%$ lower than the design frequency, $44.3 \mathrm{GHz}$. The highest effective radiated power (ERP) is $200 \mathrm{~mW}$. The effective transmitter power (ETP) defined by Gouker [10] is low, only $5 \mathrm{~mW}$. The total de power supplied was $272 \mathrm{~mW}$.

The far-field radiation patterns of the grid were measured and are shown in Fig. 8. The theoretical patterns are for a uniformly excited array of 36 short dipoles spaced $2.75 \mathrm{~mm}$ apart in the $\mathrm{H}$-plane and $2.25 \mathrm{~mm}$ apart in the E-plane and placed $5.8 \mathrm{~mm}$ in front of a mirror. Both $\mathrm{E}$ and H-plane patterns have side lobes about $10 \mathrm{~dB}$ lower than the main beam. No evidence of substarte-modes is seen. By changing the position of the mirror and the tuning slab the oscillator can

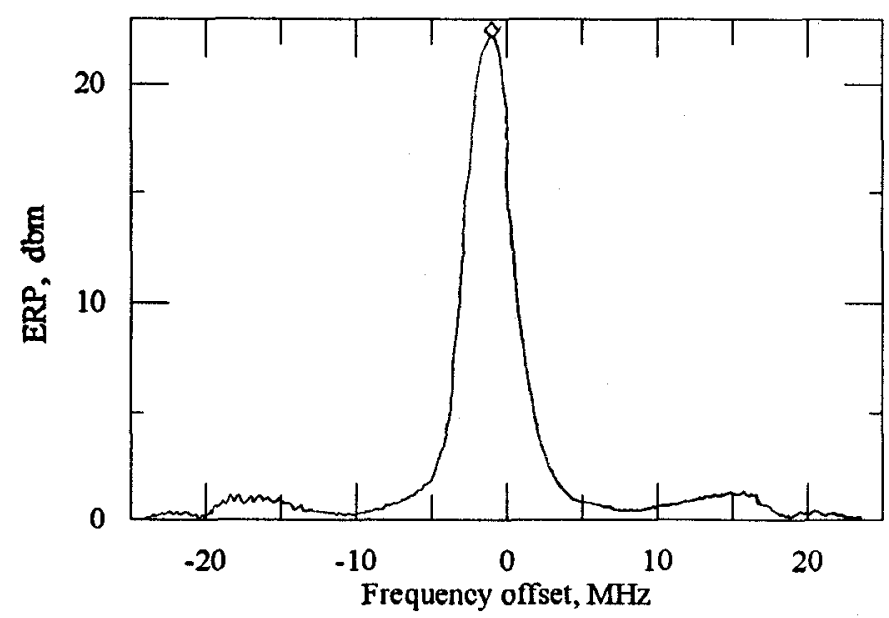

Fig. 7. Oscillation spectrum. The center frequency is $42.94 \mathrm{GHz}$.

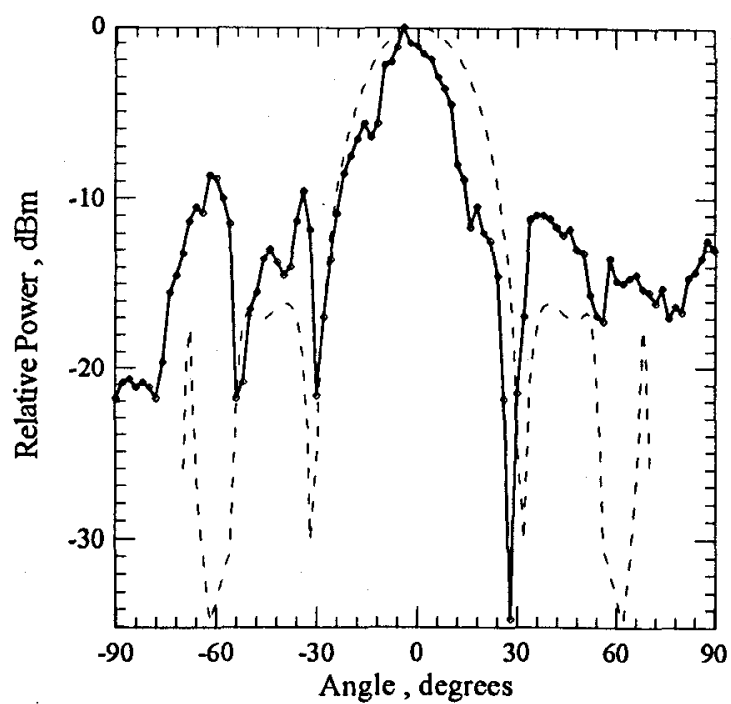

(a)

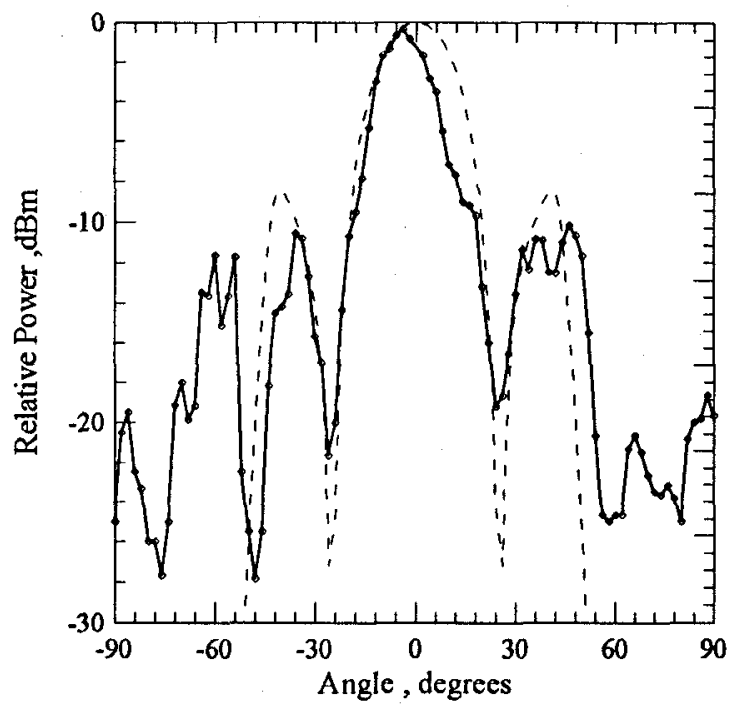

(b)

Fig. 8. Measured E-plane (a) and H-plane (b) patterns (solid lines) with $6 \mathrm{~mm}$ mirror spacing and theoretical patterns (dashed lines) with $5.8 \mathrm{~mm}$ mirror spacing.

be tuned to operate at other frequencies and different power levels. These tuning curves are shown in Fig. 9. The ERP and frequency repeat at half-wavelength intervals.

\section{CONCLUSIONS}

A 43-GHz 36-element grid oscillator has been demonstrated with an ERP of $200 \mathrm{~mW}$. The grid was designed to reduce substrate-mode excitation. This grid also demonstrated that hybrid circuit techniques can be used for quasi-optical grids at millimeter-wave frequencies. The electrical thickness and the geometry of the array (spacing of the devices) can control the excitation 


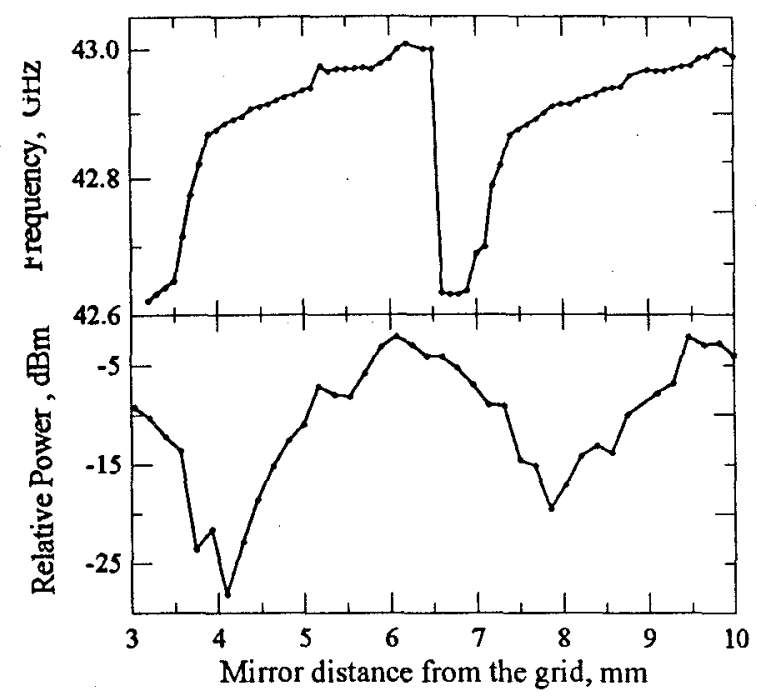

Fig. 9. Frequency and power tuning of the grid as a function of mirror position. For these measurements a dielectric slab was placed $6.5 \mathrm{~mm}$ in front of the grid.

of substrate modes.

\section{ACKNOWLEDGMENTS}

We appreciate the support of the Army Research Office and the Physical Optics Corporation. We would like to thank Freddie Williams for his help on mounting and wire-bonding the devices to the grid.

\section{REFERENCES}

[1] Z.B. Popovic, R.M. Weikle, M.Kim, D.B. Rutledge, "A 100-MESFET Planai Grid Oscillator," IEEE Trans. Microwave Theory Tech., MTT-39., pp. 193200, Feb. 1991.

[2] J.B. Hacker, M.P. De Lisio, M. Kim, C.-M. Liu, S.J. Li, S.W. Wedge, D.B. Rutledge, "A 10-Watt XBand Grid Oscillator," 1994 IEEE MTT-S Int. Microwave Symp. Dig., pp. 823-826, 1994.

[3] M. Kim, E.A. Sovero, R.M. Weikle, J.B. Hacker, M.P.De Lisio, D.B. Rutledge, "A $35 \mathrm{GHz}$ HBT Monolithic Grid Oscillator", Proc. SPIE, 17th Int. Conf. on Infrared and Millimeter Waves, R.J. Temkin, Ed., pp. 402-403, 1992.

[4] M.Kim, "Grid Amplifiers," Ph.D. Thesis, California Institute of Technology, Pasadena, CA, 1993.

[5] D.W. Griffin, "Monolithic Active Array Limitation Due to Substrate Modes," 1995 IEEE AP-S Int. Symp. Dig., pp. 1300-1303, 1995.

[6] M. Matloubian, L. Jelloian, A.S. Brown, L.D. Nguyen, L.E. Larson, M.J. Delaney, M.A. Thompson, R.A.
Rhodes, J.E. Pence, "V-Band High-Efficiency HighPower AlInAs/GaInAs/InP HEMT's," IEEE Trans. Microwave Theory Tech., MTT-41., pp. 2206-2210, Dec. 1993.

[7] M. Matloubian, L.D. Nguyen, A.S. Brown, L.E. Larson, M.A. Melendes, M.A. Thompson, "High Power and High Efficiency AlInAs/GaInAs on InP HEMTs," 1991 IEEE MTT-S Int. Microwave Symp. Dig. Vol. 2, pp. 721-724, 1991.

[8] R.M. Weikle, "Quasi-optical planar grids for Microwave and Millimeter-wave Power Combining," Ph.D. Thesis, California Institute of Technology, Pasadena, CA, 1992

[9] R.D. Martinez, R.C. Compton, "A General Approach for the S-Parameter Design of Oscillators with 1 and 2-Port Active Devices," IEEE Trans. Microwave Theory Tech., MTT-40., pp. 569-574, March 1992.

[10] M.Gouker, "Toward Standard Figures-of-Merit for Spatial and Quasi-Optical Power-Combined Arrays," IEEE Trans. Microwave Theory Tech., MTT-43., pp. 1614-1617, July 1995. 